This item was submitted to Loughborough's Research Repository by the author.

Items in Figshare are protected by copyright, with all rights reserved, unless otherwise indicated.

\title{
Two concepts of attachment to rules
}

PLEASE CITE THE PUBLISHED VERSION

http://dx.doi.org/10.1177/1468795X09344450

PUBLISHER

SAGE Publications / @ The Author(s)

VERSION

AM (Accepted Manuscript)

LICENCE

CC BY-NC-ND 4.0

REPOSITORY RECORD

Greiffenhagen, Christian, and Wes Sharrock. 2019. "Two Concepts of Attachment to Rules". figshare. https://hdl.handle.net/2134/14197. 
This item was submitted to Loughborough's Institutional Repository (https://dspace.lboro.ac.uk/) by the author and is made available under the following Creative Commons Licence conditions.

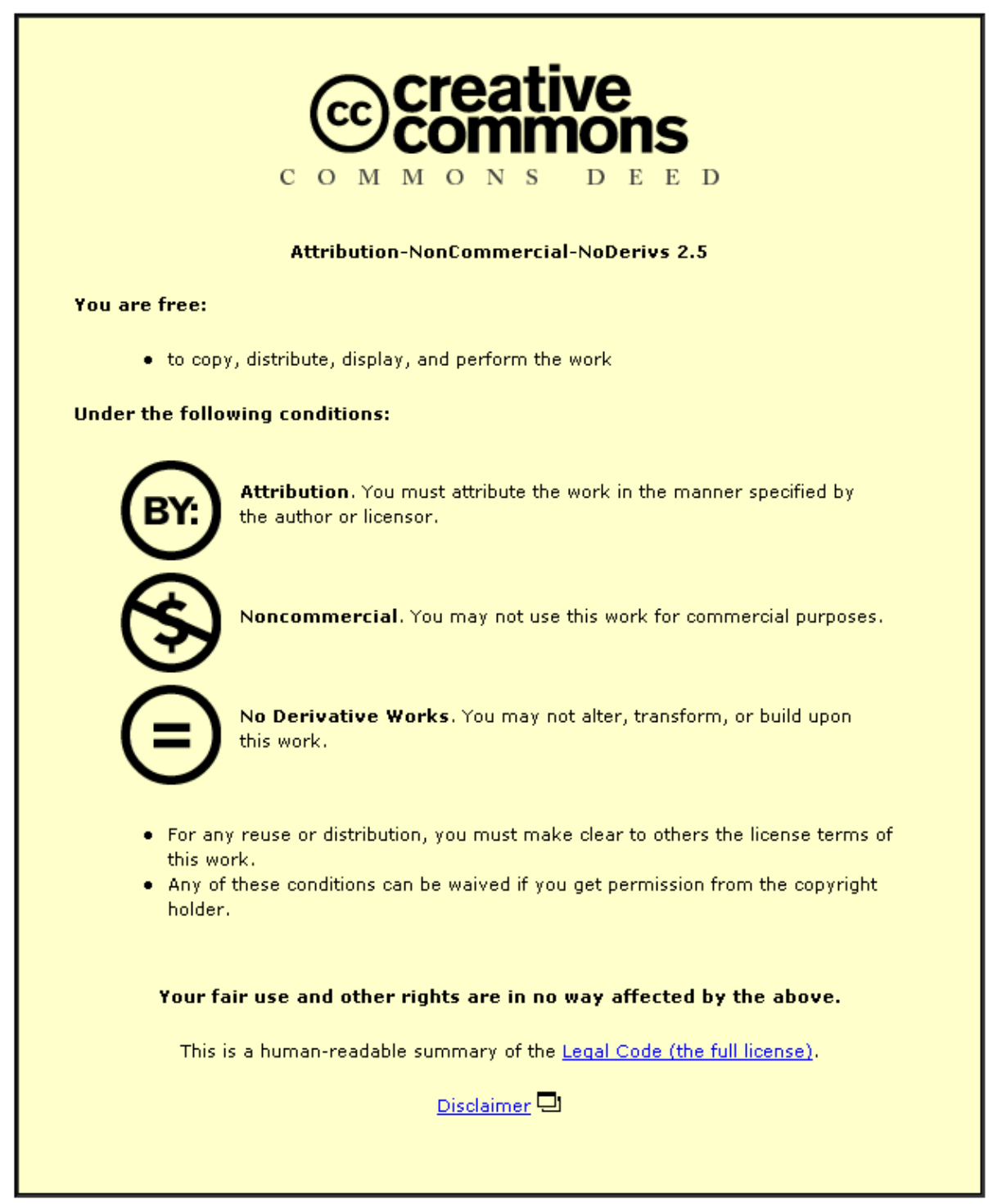

For the full text of this licence, please go to: http://creativecommons.org/licenses/by-nc-nd/2.5/ 


\section{Two concepts of attachment to rules}

Authors: Christian Greiffenhagen and Wes Sharrock

Address:

Christian Greiffenhagen

School of Social Sciences

University of Manchester

Manchester M13 9PL

UK

Email: christian.greiffenhagen@manchester.ac.uk

Version: June 26, 2009

Greiffenhagen, C. and W. Sharrock (2009). Two concepts of attachment to rules. Journal of Classical Sociology 9 (4), 405-427. 


\title{
Two concepts of attachment to rules
}

\begin{abstract}
In this paper, we discuss the implications of John Rawls’ (1955) paper “Two concepts of rules" for social science. We argue that Rawls' notion of 'practice' is not a straightforward contribution to sociological theory, but rather re-orients the idea of what understanding social actions might consist of. We explicate how Rawls' distinction between 'summary' and 'practice' views of rules might play out in approaching mathematical practice and mathematical expressions. We argue that social constructivists like Bloor hold on to a 'summary' conception of rules while Wittgenstein adopts the more radical 'practice’ conception.
\end{abstract}

\section{Keywords}

Rawls; rules; practice; Bloor; Wittgenstein; ethnomethodology 


\section{Two concepts of attachment to rules}

\section{Introduction}

Half a century after John Rawls highlighted the notion of 'practice' for the understanding of action (Rawls 1955), it is questionable as to whether sociology has, as yet, understood what Rawls' arguments meant for it, let alone caught up with Rawls. As we understand its implications for sociology, Rawls' notion of 'practice' and the associated notion of 'rule' - does not mean business-as-usual, treating these notions as putative theoretical concepts which contribute to a schematic explanation of human action, but rather re-orients the idea of what understanding social actions might consist of.

Rawls pointed to the difference between justifying an action within a practice and justifying a practice itself. Although Rawls' explicit topic was moral philosophy, it is clear that his remarks are relevant to the social and human sciences in general. We wonder whether despite the recent 'turn to practice' (e.g., Schatzki et al., 2001) the lessons about the explanatory role of rules that could have been drawn from Rawls' arguments have actually been taken. In our view, there is still a widespread misunderstanding of the relation between actions that fall under a practice and the practice to which they belong. As we shall argue here, using the example of (elementary) mathematical practice, the re-orientation that Rawls proposed is not to be identified with or reduced to a concern for the 'subjective meaning' of action but involves an understanding of the forms that actions-in-practices take.

\section{Rawls: external versus internal justification}

In “Two concepts of rules”, Rawls (1955) engages in a defence of utilitarianism, in particular with respect to its connection with punishment and the obligation to keep promises. Rawls aims to show that in discussions surrounding utilitarianism, critics tend to confuse two different kinds of justification:

In this paper I want to show the importance of the distinction between justifying a practice and justifying a particular action falling under it, and 
I want to explain the logical basis of this distinction and how it is possible to miss its significance. (p.3; our emphasis)

Rawls argues that actions done as part of a practice are justified by reference to the rules of that practice and that this kind of justification has to be differentiated from justifying the existence of the practice in the first place. Explaining why it is right that some individual is sent to jail is to be done in terms of the rules of the currently existing legal code, i.e., by mentioning the nature of the offence, the verdict, the rules of sentencing and the like (for example: convicted of aggravated assault there is a mandatory minimum sentence of three years). It is a different matter to explain why people are put in jail at all (i.e., what the 'point' of jails is) and whether imprisonment is a useful, effective, or even desirable thing to be doing. What provides answers to the first question provides no answers to the second.

In order to explain why philosophers overlook the differences between these two kinds of justification, Rawls introduces his two conceptions of rules:

To explain how the significance of the distinction may be overlooked, I am going to discuss two conceptions of rules. One of these conceptions conceals the importance of distinguishing between the justification of a rule or practice and the justification of a particular action falling under it. The other conception makes it clear why this distinction must be made and what is its logical basis. (p.4)

According to the first view, rules are seen as summaries of past cases, i.e., "[i]f a case occurs frequently enough one supposes that a rule is formulated to cover that sort of case” (p.19). With regard to the summary conception, particular cases are thus treated as logically prior to rules:

We are pictured as recognizing particular cases prior to there being a rule which covers them, for it is only if we meet with a number of cases of a certain sort that we formulate a rule. Thus we are able to describe a particular case as a particular case of the requisite sort whether there is a rule regarding that sort of case or not. Put another way: what the A's and the $B$ 's refer to in rules of the form 'Whenever $A$ do $B$ ' may be described as $A$ 's and $B$ 's whether or not there is the rule 'Whenever $A$ do $B$ ', or 
whether or not there is any body of rules which make up a practice of which that rule is a part. (p. 22)

In other words, under the summary conception rules are not seen as constitutive of the sense of $A$ and $B$. In contrast, according to the practice conception, rules are treated as logically presupposed in the identity of particular cases, i.e., "are pictured as defining a practice” (p. 24):

In the case of actions specified by practices it is logically impossible to perform them outside the stage-setting provided by those practices, for unless there is the practice, and unless the requisite properties are fulfilled, whatever one does, whatever movements one makes, will fail to count as a form of action which the practice specifies. (p. 25)

According to the practice view, actions cannot be recognized as $A$ and $B$ independently of the rule. So, on this practice view, the rule comes before particular cases. Consequently, justifications of actions are internal to a practice: to characterise a particular action as 'assault' presupposes the justice system; similarly, to characterise the playing of a card as ‘drawing trump' presupposes the rules of Bridge.

Note that Rawls is not saying that there are no rules that fit the summary conception, but that the summary conception has been inappropriately treated as conceptualising rules in general. Many recipes and heuristics may fit the summary conception of rules (since a particular recipe for, e.g., cooking a chicken is not constitutive of what cooking a chicken consists of, but is rather a very good way of doing so, often based on past experiences), but not all rules have such a summary character, since other rules are actually constitutive of the practice they specify (cf., Garfinkel, 1963). Rawls argues that the summary conception hides that certain rules do not have a summary character, whereas the practice conception highlights that these kinds of rules do not regulate a pre-existing kind of action, but introduce the kinds of actions that the rules will subsequently regulate.

A good way of illustrating the two different kinds or conceptions of rules is with respect to a game like chess. The rules of chess which define, for example, how particular pieces can move and when a player is 'checkmate', are not summaries of 
past actions of playing the game, but rather define those actions as moves within chess. In contrast, chess strategies (for example, the different kinds of openings, such as the English Opening or the Sicilian Defence) are not constitutive of the game of chess at all, but rather are summaries of successful ways of playing ('rules of preferred play’ in Garfinkel’s terms).

\section{Implications for social science}

Rawls' distinction between two different conceptions of rules and his emphasis on the action-constitutive nature of a practice's rules have not passed unnoticed in social science and have often enough been pointed out. However, we wonder whether social science has not misunderstood what the consequences for its enterprise would be. The consequences are, we think, quite profound, and our effort here will be (another) exercise in clarification - to explain as clearly as possible, and to illustrate, what the implications for social science are.

As already noted, Rawls' argument is not that all rules are part of a practice (it is not his purpose to reject the summary view for all cases), but to show that the summary view of rules has inappropriately been taken as giving the general picture of all rules. Hence, it is certainly not necessary to make the reverse error and suppose that all activities are conducted under some practice. All that follows from Rawls' argument is that a society features numerous practices and that the requirements for understanding actions within a practice differ from actions that fit the summary conception of rules (which differ, again, from those actions that are not actionsaccording-to-a-rule).

Rawls' emphasis on the notion of practice is then not a straightforward contribution to sociological theory, but rather results in complications for finding answers to the question "Why are these people doing what they are doing?”. Rawls highlights that answers to that question are not alike, since different kinds of actions afford different kinds of justification. Rawls turns attention to the question of "What are these people doing?” and the problems in (a) the identification of actions, and (b) the specification of the '(social) forms' they take.

Greiffenhagen, C. and W. Sharrock (2009). Two concepts of attachment to rules. Journal of Classical Sociology 9 (4), 405-427. 
As Rawls makes plain, in many cases, a practice logically precedes its individual instances, i.e., the basis for identifying an action is given in and by the practice. The action is identifiable as a regular occurrence not on the basis of observing other actions, but on the basis of its relationship to the normal or standard ways of the practice. The capacity to identify actions-under-a-practice does not come from the observational enumeration (aggregation) of occurrences, but rather from understanding the application of the requirements of the practice in each case.

This is not a matter of 'taking the actors' point of view' in the sense of seeking their 'subjective' views (cf., Greiffenhagen and Sharrock, 2008), but a matter of delineating their practical familiarity with the 'action forms' that the practice makes available. For a canonical example, someone who recites "one, two, three, four, five, ...” is obviously engaged in counting, and it is understood by all that this recitation has been given in a correctly ordered, predictably extensible sequence, i.e., that it is a reproduction of a standardised number system. These understandings are available to us because we are familiar with the practice of counting and because we have a thoroughly practical grasp on the fact that carrying out such instant activities involves the employment of a number system. We can recognise the action forms of, for example, counting, counting by twos, or addition, since these are constituted by the standard number system that is institutionalised in the society. The identity of an action-under-a-practice - what action it is - is then not a matter of 'subjective understanding', since what establishes the identity of an action is not the actor's (subjective) intent per se, but whether or not what is done satisfies the requirements of the practice. For example, a sequence of 2, 4, 6, 8, 13 does not satisfy the requirements for 'counting by twos' regardless of the actor's intent.

Insofar as sociological theorising is concerned with actions, it then follows that the identification of actions in cases of actions-under-a-practice is not the privilege of the theorist, but is regulated by the ways of the relevant practice. For example, what constitutes a 'correct' move in chess is not to be answered by the sociologist, but rather by reference to the rules of chess. Consequently, the adequate identification of actions in such cases presupposes an understanding of the ways in which the practice operates.

Greiffenhagen, C. and W. Sharrock (2009). Two concepts of attachment to rules. Journal of Classical Sociology 9 (4), 405-427. 
The question then is not whether 'practice' might be an indispensable concept for sociological theory (it is clear that it is), but rather what the existence of practices implies for the project of social science. Rawls did not pretend to reveal to philosophers the existence of legal practices (they already knew about them), but rather drew out the implications of the existence of different practices for making philosophical arguments about punishment and promises. Following Rawls, we would argue that sociologists are by virtue of their lives in the society and their reliance on their vernacular competences thoroughly familiar with a whole range of practices, but that they pervasively overlook (even though they presuppose) the existence of those practices in their 'sociological' discourse.

Finally, following Garfinkel (1967) we want to note that the understanding of activities in terms of a practice is in no way something that is distinctively done by those who carry the professional title 'sociologist', since ordinary members as part of their activities have to identify what the relevant practice is in order to behave appropriately. The implication for the project of social science is to move from the motivational question of "Why do people act in the way that they do?" to the 'procedural' question of “How do they do the things they do?”

\section{Social constructivism}

Rawls' position may seem very close to that of what is often referred to as 'social constructivism' in social science. The aim of social constructivists (we will take Bloor as our example) is to counterpose contingency to necessity, i.e., to demonstrate that practices could be otherwise. Since our practices (including science and mathematics) are subject to socio-cultural variation, the social constructivist concludes that there is nothing necessary about the forms of our practices (in particular: we could have a different form of mathematics).

Rawls seems to engage in a similar argument: by drawing a distinction between judgements within a legal system and the justification of that legal system, Rawls is simultaneously entertaining the possibility that there are different possible legal systems. Consequently, legal systems could be seen as not 'natural' but 'social' constructs, i.e., they could be (and often have been) otherwise. In our view, Rawls and the social constructivist do not differ on whether certain practices are customs, but Greiffenhagen, C. and W. Sharrock (2009). Two concepts of attachment to rules. Journal of Classical Sociology 9 (4), 405-427. 
what implications can be drawn from this. It is here that we feel that Rawls is (like Wittgenstein) much more radical than the social constructivist.

For the social constructivist, the insight that a certain practice is a social custom is a destabilising one. Bloor (1994, p. 21) defines the task of the sociologist of knowledge as confronting general and institutionalised preconceptions about whether certain practices are customs by showing that they are (no more than?) conventional forms. In contrast, in our reading of Rawls, the realisation of the social nature of a practice does not carry destabilising implications, especially not revisionist ones for an ongoing practice. For example, Rawls' argument does not seem to have implications for a particular legal practice (e.g., with respect to the verdicts that judges are handing down within a particular legal system). Rather, Rawls’ reflections have implications for moral and legal philosophy, i.e., for analysts who conceptualise and evaluate legal systems. It this analytical job of thinking about practices that is being changed through Rawls' arguments - not the actors' practices (or their conceptions of those practices).

Rawls complicates the analytical job of justifying practices by pointing to the different kinds of justification, in particular, the different offices that 'do' justifications:

Is this person the legislator, or the judge, or the body of private citizens, or what? It is utterly crucial to know who is to decide such matters, and by what authority, for all of this must be written into the rules of the institution. Until one knows these things one doesn't know what the institution is whose justification is being challenged; [...]. (Rawls, 1955, p. 11)

In other words, Rawls emphasises that with respect to justification it is important to bear in mind the kind of office that is doing the justification. In the case of legal practices, Rawls points to the difference between, in particular, the office of the judge and the legislator. The former justifies a particular action (e.g., a sentence of five years jail time) in terms of the currently available legal rules, i.e., within the practice. In contrast, the legislator is reflecting about the purpose of certain legal practices in themselves, e.g., whether jail sentences are the right kind of punishment in the $21^{\text {st }}$ Greiffenhagen, C. and W. Sharrock (2009). Two concepts of attachment to rules. Journal of Classical Sociology 9 (4), 405-427. 
century. According to Rawls, it is only in the context of this second kind of justification that arguments from the doctrine of utilitarianism can enter. Put slightly differently, the office of the judge is relatively free from 'philosophical' arguments, whereas the office of the legislator might not be. The question "Why are people put in jail?” is not a question that judges qua judges need or should address - but one that philosophers, and possibly legislators, might ask.

When Rawls' considerations are applied to mathematics, it is important to bear in mind that there is no equivalent office to that of the legislator or reformer. In our view, the two most important 'offices' to consider are the everyday user and the philosopher of mathematics. The question "Why does $2+2=4$ ?" will ask for different kinds of ‘justification’ from each. The user will presumably simply point out that this is how calculation is defined. In contrast, the philosopher may be tempted to interpret the question as asking "What makes mathematical propositions true?”. In other words, we think that Rawls' focus on the practice of punishment may enable the wrong sort of conclusion to be drawn about the more general application of his conception of practice. In the case of punishment, not only is there the practice, but there is also a demand for justification ("Why are people put in jail?") and disagreements over whether the practice is called for (“Are jail sentences justified?”). The same situation does not, however, apply with other practices such as, e.g., driving on the left/right or playing chess: when they are done as expected no justification is required.

In our view, Rawls argues for what has come to be referred to as a non-foundationalist treatment of practices, whereas social constructionists' conceptions of practice tend to be more continuous with those of foundationalism. In other words, social constructivists assume that practices presuppose basic justifications, ones which motivate participants' attachment to the practice. According to this view, people engage in a given socio-cultural practice because they believe that that practice is right. In line with a long-standing sociological conviction, social constructivists suppose that the justifications of practices are effected by naturalising the practice. In other words, it is assumed that people suppose that a particular practice is 'right', because it is in the nature of things. This accounts for social constructivists' critical 
preoccupation with (philosophical) doctrines which seek to show that practices (e.g., science or mathematics) are grounded in some external source (e.g., in reality or logic). Social constructivists are further inclined to treat those philosophical doctrines as equivalent to the beliefs of actors engaged in that practice. For example, 'realism' is pervasively treated as the working philosophy of practicing scientists (e.g., Barnes et al., 1996, p. 81) - whereas mathematicians are characterised as subscribers to Platonism or Formalism (e.g., Davis and Hersh, 1981, p. 312). Social constructivists thus suppose that showing that a practice is not grounded 'in the nature of things' will potentially destabilise it. In contrast, Rawls' separation of the two forms of justification gives grounds for questioning the supposition that people are attached to a practice by virtue of a foundational justification.

In the following we will try to show how the failure to distinguish summary from practice conceptions of rules leads David Bloor into a suspect foundationalist account of mathematics as a social practice (Bloor 1973, 1976, 1983, 1994, 1997). To illustrate the general argument we will focus on his treatment of the question of whether 2 plus 2 must equal 4 (Bloor, 1994; Barnes et al., 1996, Chapter 7).

\section{Bloor: the conventional character of mathematics}

Bloor's overall aim is to demonstrate the conventional character of mathematical knowledge:

Sociologists are professionally concerned with the conventional aspects of knowledge. So I will try to identify the conventional components of the concepts '2' and '4' and 'addition'. Conventions are shared ways of acting that could in principle be otherwise. [...] Demonstrating conventionality therefore involves demonstrating alternative possibilities. (Bloor, 1994, p.

21)

For Bloor, any insistence that $2+2$ must equal 4 seems to be an expression of a universalist conception of mathematics, which for him is as misguided as the view that a particular country's rules of traffic are universal (rather than local). Bloor's goal is to show that the equation ' $2+2=4$ ' is not universal (as, he assumes, it seems to the members of society), but only conventional.

Greiffenhagen, C. and W. Sharrock (2009). Two concepts of attachment to rules. Journal of Classical Sociology 9 (4), 405-427. 
Bloor thinks that people's belief in the universality of mathematical expressions means that, whenever they are called upon to complete ' $2+2=$ ' they will assume that they have no freedom of choice, i.e., no alterative but to write 4. If Bloor is able to demonstrate that mathematical expressions are conventional, then he believes this would show them that there is no actual constraint on what they do, i.e., that they could answer 0 , 3, or 72 and that the seeming necessity to write 4 was only a socially created illusion.

Bloor's starting point is a self-declared finitist conception of mathematics (e.g., 1994, p. 25; 1997, Chapter 2) that argues that the truth of $2+2=4$ is empirically demonstrable, but that its truth is only assured as far as it has been demonstrated. In other words, the correctness of $2+2=4$ rests only on an aggregate sample of cases (although $2+2=4$ purports to be correct in all cases). There is thus no sound basis for confidence that the rule must turn out to apply in all hitherto unexamined instances.

For Bloor it is obvious that mathematical expressions are not universal, but he seems puzzled as to why so many people believe that they are. In other words, Bloor seeks to understand what it is that makes people believe that $2+2$ must equal 4 . Bloor thinks that there are two mistaken doctrines which encourage the view that mathematical expressions are universal, namely empiricism and logicism. That is to say, Bloor thinks that most people who have to justify why $2+2$ equals 4 would hold, either, that the equation expresses an empirical fact about nature, or, that it expresses a logical principle. Bloor's aim is to show that neither empiricism nor logicism provides a justification for $2+2=4$, and that arithmetic is therefore conventional. Bloor thus extends Mannheim’s project of demonstrating the existential determination of knowledge to mathematics:

The existential determination of thought may be regarded as a demonstrated fact in those realms of thought in which we can show [...] that the process of knowing does not actually develop historically in accordance with immanent laws, that it does not follow from the 'nature of things' or from ‘pure logical possibilities’ [...]. (Mannheim, 1936, p. 239)

Greiffenhagen, C. and W. Sharrock (2009). Two concepts of attachment to rules. Journal of Classical Sociology 9 (4), 405-427. 
Following Mannheim, Bloor wants to show that $2+2=4$ neither follows from the 'nature of things' (empiricism) nor from ‘pure logical principles’ (logicism).

First, Bloor addresses the question whether $2+2=4$ might be an empirically grounded truth, i.e., a reflection of an immutable fact of nature. To demonstrate the falsehood of that idea, Bloor invites us to imagine someone who initially accepts the universal truth of $2+2=4$ (on the basis of counting apples, cows, etc.), but then, in an experimental spirit, decides to test out this truth on a plurality of further cases. In many cases, $2+2=4$ works, but is it not presumptuous to suppose that because, so far, $2+2$ have turned out to equal 4, it must always do so?

Bloor gives an example designed to show that, in an inductive spirit, one might find a case in which it just does not turn out that way. Imagine encountering a wheel that is segmented into four bits marked '0', ' 1 ', ' 2 ', and ' 3 '. Try adding these numbers! How does one do that? Treat rotation of the wheel as 'addition', so that, positioning the wheel at the starting point 0 one can move the wheel through two points, and treat that as 'adding 2'. Therefore 0 'add' 2 'equals' 2 , in symbols: $0+2=2$. Similarly, 0 $+1=1$ (starting at position 0 moving one position) and $1+2=3$ (starting at position 1 moving two positions), confirming earlier 'hypotheses'. However, what happens if we start from position 2 and move through two further points? In Bloor's (1994, p. 26) own words: "we make the inevitable discovery: we set the wheel at 2, and then turn it to so as to add a further 2 , and we get back to zero. $2+2=0$.”

The number wheel example (which is really arithmetic modulo 4) for Bloor falsifies the empirical hypothesis that $2+2$ is always 4 . According to Bloor, one is now faced with the problem that in many situations $2+2=4$, but in some situations $2+2 \neq 4$. What is to be done?

According to finitism, there is no 'correct' response implicit in what went before. It isn't a case of 'discovering' the right status to accord the discovery that $2+2$ can add up to something other than 4 . It is a case of deciding. The existing state of culture, the context around the new result, and the interests that inform our practices, will all impinge on the decision. (Bloor, 1994, pp. 26-27). 
That is to say, the truth of $2+2=4$ is not justified empirically, because $2+2=0$ on the number wheel also corresponds to the 'nature of things'. It is therefore not nature, but society, through its conventions, that determines that $2+2$ equals 4 (and not 0 ).

Bloor is aware that he has so far only 'refuted' empiricism. What about the possibility that $2+2=4$ follows from 'pure logical possibilities'?

Now for the second obstacle. This concerns proofs. Surely if we can prove that $2+2=4$, then all this talk of 'discretion', and 'moving from case to case', as if each step were creative and problematic, must be wrong. (Bloor, 1994, p. 27)

Bloor investigates attempts to prove $2+2=4$ formally. Such proofs are part of relatively recent developments in mathematics and belong to a field variously known as metamathematics, the foundations of mathematics, or formalism. Bloor, following Mackie (1966) argues that formal proofs of $2+2=4$ do not succeed for they rely on the very result they aim to prove: ${ }^{1}$

It shows us that these same conventional procedures or techniques are presupposed by the rigorous proof. Rather than this proof representing some principle of knowing, or some avenue to knowledge, that is superior to the conventionalized procedures of arithmetic, it presupposes them. (Bloor, 1994, p. 29)

Bloor has thus demonstrated the inadequacy of the two standard justifications that $2+$ 2 has to equal 4. The equation neither follows from the 'nature of things' nor from ‘pure logical possibilities’ and, he argues, is consequentially existentially determined, i.e., a conventional matter.

\footnotetext{
${ }^{1}$ We do not discuss the technical details of this discussion, since we agree with Bloor that formal proofs of $2+2=4$ fail to provide a justification for that equation. As will become clear, our disagreement concerns the question in which sense $2+2=4$ can be justified in Bloor's terms in the first place.
}

Greiffenhagen, C. and W. Sharrock (2009). Two concepts of attachment to rules. Journal of Classical Sociology 9 (4), 405-427. 


\section{The summary view of mathematical expressions}

Bloor rightly treats $2+2=4$ as a rule. However, as Rawls points out, the important question is to discern what kind of rule this might be.

Bloor self-avowedly adopts a finitist conception of rules, i.e., for him a rule is justified by the applications of the rule so far. So far the calculations have conformed to the rule, but there can be no evidence that this will be so in the next case, or the one after that. It should be clear that Bloor's finitist conception is equivalent to what Rawls terms the summary view of rules, which is characterised by assuming that "[i]f a case occurs frequently enough one supposes that a rule is formulated to cover that sort of case” (Rawls, 1955, p. 19). This is Bloor's position, since he asks us to imagine that the rule $2+2=4$ is a result of having performed a number of counting activities in the world (e.g., putting apples together) and since it was (always? nearly always?) the case that two apples put together with two apples gave four apples, we have formed the rule $2+2=4$. In other words, the number wheel example imagines a person who has so far only encountered particular cases where $2+2=4$, and who is therefore surprised when he or she 'discovers' that there can be cases where $2+2 \neq 4$. Bloor further presupposes that those who participate in the practice of arithmetic do so on the basis of such a summary view, i.e., they suppose that because the rule has so far applied, it will continue to do so. The number wheel example is Bloor's attempt to show that not only is there no logical necessity to make this assumption, but that it is also factually incorrect.

Bloor's view of mathematical expressions shares three properties that Rawls identified as being characteristic of a summary conception of rules:

1. The point of having rules derives from the fact that similar cases tend to recur and that one can decide cases more quickly if one records past decisions in the form of rules. (Rawls, 1955, p. 22)

In the case of mathematics, the similar cases concern instances of 'adding things together'; the rule $2+2=4$ is formed as a result of the fact that previously when we have put two things together with another two things we get four things.

Greiffenhagen, C. and W. Sharrock (2009). Two concepts of attachment to rules. Journal of Classical Sociology 9 (4), 405-427. 
2. The decisions made on particular cases are logically prior to rules. [...] We are pictured as recognizing cases prior to there being a rule which covers them, for it is only if we meet with a number of cases of a certain sort that we formulate a rule. (p. 22)

Bloor's picture of the formation of mathematical rules sees the particular cases as independent and prior to arithmetic systems. 'Adding' in the apple case and the number wheel case are seen as the same activity of 'counting' independent of and prior to the system of arithmetic that is being applied. In other words, Bloor argues that from doing the same thing one can get different results (whereas our point will be that in the two examples one is not doing the same thing).

3. Each person is in principle always entitled to reconsider the correctness of a rule and to question whether or not it is proper to follow it in a particular case. (p. 23)

Bloor's example of the number wheel is not meant as the discovery of a new kind of game/practice, but rather a reflection on the correctness of the rule $2+2=4$. Bloor is using the example to get the reader to question whether this rule should be followed in the case of the number wheel. The overall message is a critical one: "You might have thought that you have always had to accept that $2+2=4$, but now you should realise that there cases where $2+2 \neq 4$. Therefore it is up to you (or society) to decide whether you want to accept that $2+2=4$.”

\section{The practice view of mathematical expressions}

Rawls has provided a basis for recognising that the summary conception of mathematical expressions might neither be the necessary, nor even the best view. How is the practice conception to be applied to mathematics? Here Wittgenstein's reflections on mathematics (e.g., 1976, 1978) provide something very like Rawls' account of the relation of utilitarianism to legal practices.

For Wittgenstein, a number of philosophical confusions arise from the temptation to treat every expression of an ostensibly propositional form as a proposition. In the case of mathematics, it is clear that mathematical expressions have some similarities to empirical propositions and in some contexts function as such. However, for Greiffenhagen, C. and W. Sharrock (2009). Two concepts of attachment to rules. Journal of Classical Sociology 9 (4), 405-427. 
Wittgenstein, it is an error to suppose that mathematical expressions always function as empirical propositions that can be readily characterised as being either true or false:

We are used to saying " 2 times 2 is 4", and the very "is" makes this into a proposition, and apparently establishes a close kinship with everything we call a 'proposition'. Whereas it is a matter only of a very superficial relationship. (Wittgenstein, 1978, I, Appendix III, §4)

Rather than thinking of mathematical expressions as (empirical) propositions, Wittgenstein asks us to see them as rules or norms. Expressions such as $2+2=4$ might superficially invite identification as a proposition, but in most situations function as a rule (as the instruction: "whenever you come across $2+2=$ then write 4 ”). ${ }^{2}$ Put slightly differently, mathematical expressions do not constitute descriptions about anything, but rather provide the forms in which descriptions may be cast:

[...] the mathematical proposition is only supposed to supply a framework for a description. (Wittgenstein, 1978, VII, §2)

What I want to say is: mathematics as such is always measure, not thing measured. (Wittgenstein, 1978, III, §75)

That is to say, we can use mathematics to form descriptions - but mathematical expressions themselves are not descriptive.

\footnotetext{
${ }^{2}$ Wittgenstein is not saying that mathematical propositions are rules rather than propositions. He does not think that there is a single correct characterisation of mathematical expressions. Rather, Wittgenstein wants to draw attention to the differences between " $2+2=4$ " and "There is a cat on the mat” and the danger of treating mathematical expressions always as a type of fact stating proposition. Wittgenstein (1976, p.251) remarks: "Of course you can say mathematical propositions are about numbers. But if you do, you are almost sure to be in a muddle. Because you don't see that what is about 2 in the sense in which a proposition is about a sofa, is never a mathematical proposition. [...] I don't say it is wrong to say that mathematical propositions are about numbers, that the other way of speaking is right. I only want to point it out. Because unless you see there are the two ways - you are likely to be misled.”
}

Greiffenhagen, C. and W. Sharrock (2009). Two concepts of attachment to rules. Journal of Classical Sociology 9 (4), 405-427. 
Good examples are systems of measurement, such as the metric or Imperial one. These measurement systems are not descriptive themselves, but can be used for descriptions (it is not in the nature of things to be either metres or feet in length, but measurement in feet or metres does state the length of, e.g., a sofa). Wittgenstein (1953, §50) notoriously denied that the question "Is the standard metre in Paris one metre long?” is an empirical one. The reason for Wittgenstein's denial is that the expression “The 'standard metre' is one metre long.” may look just like an empirical proposition (which is either true or false), but its function in the metric system is not that of an empirically testable claim, but rather than of a stipulation: whether anything is a metre long is to be decided by matching it against the standard metre. In Wittgenstein's words: “In this language-game it is not something that is represented, but is a means of representation” (1953, §50). In Rawls’ terms, the standard metre has to be treated as constitutive of the practice of measuring-in-metres.

Wittgenstein's remarks about the standard metre are meant to illustrate his general warning that many statements only misleadingly resemble empirical propositions. Rather than just looking at the form of statements, he invites us to pay attention to their sense and to note that, for example, the sense of "That table is two metres eighteen centimetres long." is very different from the sense of "The standard metre is one metre long.”. The first might be either an empirical hypothesis or the report of a measurement (depending on whether it comes before or after the measurement being made), whilst the second is neither a hypothesis nor a report of measurement using the metric system, but is itself (insofar as it makes sense at all) part of the metrical measurement system. It is something said in explaining how the metric system works and as such it is a stipulation of what the definitive standard of metric measurement is:

A thing cannot be at the same time measure and the thing measured. (Wittgenstein, 1978, I, §40, footnote 1)

If you measure a table with a yardstick, are you also measuring the yardstick? If you are measuring the yardstick, then you cannot be measuring the table at the same time. (1978, III, §74)

Greiffenhagen, C. and W. Sharrock (2009). Two concepts of attachment to rules. Journal of Classical Sociology 9 (4), 405-427. 
The metric system itself does not dictate that the length of the table is two metres eighteen centimetres, but rather details what sorts of measuring operations will yield a correct measurement of the table (where the results of those measuring operations will depend upon the table being measured). An understanding of how the metric system works as a means of measurement thus enters into the sense of claims about the length of the table. The metric system is a standard of correctness, and standards of correctness are in themselves neither correct nor incorrect, but are rather presupposed in determinations of what is and is not correct.

Wittgenstein adopts a practice conception of mathematical expressions, which has the features that Rawls specifies:

In contrast with the summary view, the rules of practices are logically prior to particular cases. This is so because there cannot be a particular case of an action falling under a rule of a practice unless there is the practice. (Rawls, 1955, p. 25)

Bloor proceeds as if we can talk of 'adding' and 'totalling' without specifying a practice. However, if one reflects on the details of the number wheel example, one can see that Bloor has not described a case in which counting according to $2+2=4$ has failed, but rather has set up a different practice using some of the notations employed in another practice. The number wheel, rather than providing counterevidence for the certainty in our belief that $2+2=4$, simply is the 'discovery' of another practice - which has a peculiar relation to our original practice, namely that it utilizes the same symbols. This resembles the realisation that with a deck of cards we cannot only play Bridge, but also Poker. However, this realisation has no implications for either Bridge or Poker.

Bloor's number wheel example demonstrates that a lot of ground-work has to be done in order to introduce 'numbers' (rather than mere symbols) which can be used to 'add'. Rawls illustrates this in the following way:

Many of the actions one performs in a game of baseball one can do by oneself or with others whether there is the game or not. For example, one can throw a ball, run, or swing a peculiarly shaped piece of wood. But one 
cannot steal base, or strike out, or draw a walk, or make an error, or balk; although one can do certain things which appear to resemble these actions such as sliding into a bag, missing a grounder and so on. Striking out, stealing a base, balking, etc., are all actions which can only happen in a game. No matter what a person did, what he did would not be described as stealing a base or striking out or drawing a walk unless he could also be described as playing baseball, and for him to be doing this presupposes the rule-like practice which constitutes the game. The practice is logically prior to particular cases: unless there is the practice the terms referring to actions specified by it lack a sense. (p. 25)

The same applies to mathematics: of course we can do things with apples that resemble counting. We can put them together, and divide them, etc. However, if we are counting or calculating then we can do so only within a system of arithmetic. We cannot ask whether $2+2=4$ without specifying (or presupposing, as normal users do) a standard or practice, since it is the standard or practice that specifies what counts as correct.

Bloor treats the activity 'counting' as the same in the case of 'counting apples' and 'counting on the number wheel'. However, the numbers on the number wheel function not like a quantity, but more as a position, akin to house numbers (but adding number 12 to next door's number 14 does not yield 26 houses). '2' on the number wheel does not signify an amount, but rather a position or location. Furthermore, one can count (in the standard sense) the number of points on the number wheel: there are four of them. Finally, one can count cumulatively the number of points through which the wheel cycles: eight points is two complete revolutions (although it would be represented in Bloor's notation as $0+1+1+1+1+1+1+1+1=0$ ). In sum, the number wheel does not establish Bloor's point that one does not have to give the prescribed answer 4 to the equation $2+2=$, i.e., that one could as well give another answer, e.g., 0. Bloor's number wheel is simply a different kind of arithmetic (arithmetic modulo 4), but in that system the answer is no less inexorable than is 4 in the standard case.

Bloor treats the necessity of arithmetic systems as though it were an extraneous and supernumerary feature of them, as though one could learn, first, the number system, Greiffenhagen, C. and W. Sharrock (2009). Two concepts of attachment to rules. Journal of Classical Sociology 9 (4), 405-427. 
and subsequently require the conviction that the operations must be strictly respected, when, with such arithmetics, the rigorous nature of the rules is part of defining the practice (learning to count is learning to recite the numbers in fixed sequence). Rawls' practice conception of rules highlights this feature of mathematical expressions:

The practice view leads to an entirely different conception of the authority which each person has to decide on the propriety of following a rule in particular cases. To engage in a practice, to perform those actions specified by a practice, means to follow the appropriate rules. If one wants to do an action which a certain practice specifies then there is no way to do it except to follow the rules which define it. Therefore, it doesn't make sense for a person to raise the question whether or not a rule of practice correctly applies to his case where the action he contemplates is a form of action defined by a practice. If someone were to raise such a question, he would simply show that he didn't understand the situation in which he was acting. If one wants to perform an action specified by a practice, the only legitimate question concerns the nature of the practice itself (“How do I go about making a will?”). (p. 26)

Bloor seems to conflate Rawls' two different kinds of justifications (of a particular action within a practice and the practice itself). In the case of mathematics this is equivalent to two different kinds of necessity. As Wittgenstein (1976, p. 241) remarks: "[w]e must distinguish between a necessity in the system and a necessity of the whole system". Within a particular arithmetic, the answer is inexorable however, there is no necessity in adopting a particular kind of arithmetic in the first place.

Bloor's objective is to show that a 'sociological' explanation of the necessity (or, more precisely, the apparent necessity) of $2+2=4$ is called for. In contrast, we have been arguing that the need for sociological explanation in Bloor's sense is itself only an apparent necessity. Our disagreement with Bloor is not over the appropriateness or otherwise of giving a sociological explanation of practices, but with something rather more specific, namely, Bloor's conception of the form that sociological explanation must take. We have tried to show that Bloor's sees a need for such sociological Greiffenhagen, C. and W. Sharrock (2009). Two concepts of attachment to rules. Journal of Classical Sociology 9 (4), 405-427. 
explanation as a result of not distinguishing sharply enough between the necessity within a particular example arithmetic (i.e., that $2+2=4$ on the number wheel) and the necessity of adopting a particular arithmetic (e.g., 'number wheel arithmetic'), i.e., between what Rawls called “justifying a practice” and “justifying a particular action falling under it”.

\section{Two concepts of attachment}

In our view, Bloor's interpretation is far from idiosyncratic, since it is a very widespread assumption across social science that individuals engage in practices on the basis of the beliefs they hold about those practices (this is, after all, the key supposition of the critique of ideology since Marx at least, which argues that these practices impose themselves by virtue of their apparent natural necessity). Such beliefs, it is often assumed, lead to the practice in question being experienced as necessitated by the essential nature of things and therefore immutable and universal. Sociologists have argued that this kind of attachment is a result of people 'naturalising' a practice's local ways, conceiving these as being in accord with the very nature of things and therefore universal (see Abercrombie et al., 1986, for a rare critique of this supposition). One prominent task of social science is thus to unmask this mistaken ‘naturalness' of people’s beliefs.

Bloor gives the following motivation for his sociological project:

Institutions and norms are more than dispositions and expectations. They are also the focus of attitudes and bring forth potent images. Wittgenstein takes account of this when he says: "Our children are not only given practice in calculation but are also trained to adopt a particular attitude towards a mistake in calculating." [...] The attitude is typified by the feeling that the calculation goes its own way, though the calculator may lapse. The theories of mathematics that Wittgenstein is opposing mistake this attitude for the whole of the reality that they are trying to explain. For institutions such as the law or the monarchy this confusion [...] would be a case of mistaking an ideology for the reality that it seeks to legitimate. Perhaps the same should be said here too. (Bloor, 1973, p. 189)

Greiffenhagen, C. and W. Sharrock (2009). Two concepts of attachment to rules. Journal of Classical Sociology 9 (4), 405-427. 
Bloor is saying that people have a particular 'attitude' toward arithmetic, which sees equations such as $2+2=4$ as natural. ${ }^{3}$ While Marx criticised classical economists for universalising the economic categories of capitalism, Bloor wants to demonstrate that people have universalised 'their' arithmetic in much the same way. Bloor thus aims to show that people's attachment to arithmetic is as ideological as their attachment toward, e.g., the monarchy.

According to Bloor, learning a practice consists of two (independent) things: (1) an understanding of the rules of that practice; (2) acquiring an attachment or commitment to the rules of that practice as the natural, correct, or only way of doing things. The important consideration for Bloor clearly is (2). When Bloor compares the rules of traffic (e.g., driving on the left) with the rules of arithmetic (e.g., base ten arithmetic), the difference for Bloor lies not in the difficulty of learning them, but in the kind of attachment people have to them. As Bloor understands it, is easier for people to acknowledge that things 'could be otherwise' in the case of rules of traffic than in the case of rules of arithmetic, i.e., Bloor thinks that people are attached in a different way to the rules of traffic than they are to the rules of arithmetic, so that whilst people realise that the rules of traffic are conventional, they are in denial about the conventional status of arithmetic. ${ }^{4}$

Bloor's arguments are not therefore an attack on the result of adding 2 and 2 (and getting 4), but an attempt to loosen our attachment to that result, i.e., an attack on our inability to acknowledge that $2+2$ could equal 3, 0, or 65 (which according to Bloor arises from the naturalising illusion we have about the practice). The point of the number wheel example is not to show that people have made mistakes when counting apples or cows, but that they were misguided about the inevitability of the equation 2

\footnotetext{
${ }^{3}$ In contrast, we think that Wittgenstein's conception of 'attitude' in the passage quoted by Bloor is more one of, e.g., stringent intolerance toward mistakes rather than a belief in the 'naturalness' of arithmetic.

${ }^{4}$ This, in our view, is a move made by many of those that claim that, for example, logic, grammar, or arithmetic are culturally relative (see Greiffenhagen and Sharrock, 2006a,b, 2007).
}

Greiffenhagen, C. and W. Sharrock (2009). Two concepts of attachment to rules. Journal of Classical Sociology 9 (4), 405-427. 
$+2=4$. Similarly, in his discussion of mathematical proofs, Bloor is not finding mistakes in previous proofs, but is questioning in which sense these proofs are absolute foundations for mathematical statements.

Bloor's target is people's alleged beliefs in the universality of mathematics (e.g., that $2+2$ must in all circumstances equal 4). However, Bloor makes the conflation that Rawls warned against, between justifying a whole practice and justifying an action in the terms of a practice. That is to say, Bloor confuses two different senses of 'must', namely (i) that we must use this arithmetic system, and (ii) that when using this arithmetic system the constitutive equations must hold. We may ask whether we should apply the 'ordinary' rules of arithmetic in any particular situation, but that question is independent from asking whether $2+2$ must equal 4 within ordinary arithmetic.

Bloor has amplified, rather than eliminated, the confusion surrounding the fact that 2 +2 must equal 4, by treating every insistence on this as if it involves an assumption about the uniqueness of this number system, regardless of whether this insistence originates with a philosophical realist or an everyday user of calculations. We have tried to show that it is perfectly possible for people to hold that $2+2$ necessarily equals 4 without manifesting attachment to, or needing emancipation from, an ideologically universalising conception of the number system, since they can be seen as simply expressing their correct understanding of the number system in which that equation appears.

This can be illustrated by the fact that someone who initially replies affirmatively to the question “Is 2 plus 2 always 4?” and is then shown the number wheel example, is not likely to respond with shock and awe (as one might expect after the unmasking of an ideology), but rather with mild amusement ("ah, what a nice little trick - yeah, I now see why you can say that 2 plus 2 does not always equal 4 - but of course this has no consequence for the calculations that I encounter every day"). Thus in our view the supposed belief in the universality of $2+2=4$ is not an expression of an ideology that has to be unmasked, but rather a function of the ubiquity of that arithmetic that features this equation in the everyday affairs of our society. Like 
Rawls' examples from baseball, it constitutes its own objects independently of other practices.

People may be said to be 'attached' to playing particular games with symbols rather than others - but that does not mean that they therefore must conclude that this is the only thing that can be done with these symbols. In other words, our 'attachment' to 2 $+2=4$ resembles the attachment of a professional Bridge player to the rules of Bridge, or the attachment of a member of one culture to certain cultural practices (e.g., forms of greeting or types of food). The rules of Bridge, traffic, or of a particular number system are not 'natural' (in contrast to 'cultural'), but that does that mean that we cannot feel deeply attached to them. "This is the only way to do it” (e.g., "Bridge is the only game there is.”) in many situations is not an ontological remark (claiming that other ways of doing things are inconceivable), but an expression of a strong preference for or entrenched attachment to that way of doing things ("I know there are other ways of doing things, but I really don't like them”).

This can be clarified by noting that 'our' system is simply the one with which everyone in our society is familiar (which has led us to label the number system in which $2+2$ does, and must, equal 4 the 'default' or 'standard' number system). That number system does not gain its default status from any mathematical properties, but from the fact that it is widely institutionalised throughout our society, where it plays a multifunctional role. It is the number system which almost everyone is socialised into early childhood - the one taught by times tables, built into early reading books, etc. As a result of its pervasiveness this system functions as the default system for identifying basic calculations. It is not that we cannot imagine other arithmetical system or even suppose that it is the only number system in commonplace use in our society (for example, we are all aware of modulo arithmetic in at least the form of the 12-hour clock, where $12=0$ ), but rather that, all other things being equal, we will assume that this is the number system in play.

To give an analogy: If we have some cards in our hands and someone plays a Queen of Spades, we would not know what card to play next - without being told which game is being played. In contrast, if we see " $7+8=$ ” written on a blackboard we would typically give 15 as the 'natural' answer. 'Natural', that is, not because of any Greiffenhagen, C. and W. Sharrock (2009). Two concepts of attachment to rules. Journal of Classical Sociology 9 (4), 405-427. 
metaphysical commitment to 'our' arithmetic, but simply because this system has something of a default status in our society. Consequently, someone who is asked whether $2+2$ must always equal 4 is entitled to assume that they are being questioned within the default system of arithmetic, and is therefore right to conclude, on the basis of that assumption, that it does. Equally, if we were to tell someone, as a bare statement of fact, without context or explanation, that it is arithmetically correct that $12=0$ and $5=9$, we might tempt people into denying that this could be so. However, we could easily point out to them that they already accept just these equations without demur in the course of their practical lives by making clear that these equations hold in the familiar contexts of the 12-hour clock $(12=0)$ and in terms of time zone comparisons between London and New York $(5=9)$ respectively. These observations highlight that use of a particular number system in accord with its internal necessities does not preclude nor conflict with the comfortable, largely thoughtless, use of other number systems in our practical affairs.

In a sense, Bloor sees the various philosophies of mathematics (Platonism, empiricism, formalism, logicism) as formulating the reasons for (ideological) attachment to arithmetic that are implicit in everyday uses of arithmetic. In contrast to Bloor, we have cast doubt on the idea that the use of arithmetic is underpinned by such quasi-philosophical doctrines. Whilst Rawls' arguments distinguish between justifying an action under a practice and justifying a practice according to a moral principle, they neither suggest nor entail that engagement within a practice (and justification within it) requires or depends upon any justification of the whole practice itself. The practice of punishment may be installed and running without need for further justification than that which comes with the practice itself. Request for further justification might be relevant for other ‘offices’ (e.g., legislators or philosophers), but not necessary for ordinary practitioners.

\section{Conclusion}

We have presented Rawls as highlighting - in a very similar way to the almost simultaneous projects of Harold Garfinkel (1967, 2002) and Peter Winch (1964, 1990 [1958]) - the extent to which society is, so to speak, a self-describing enterprise. In our view, the argument of these authors could be summarised as saying that for an 
extensive range of the problems that puzzle social scientists perhaps the first, and largely unsatisfied, requirement is to ensure that the practices under consideration are correctly specified, which involves in extensive part understanding how the selfdescriptive capacities of a practice operate. The 'perhaps' marks the idea that the satisfaction of this requirement may be sufficient and may - as we have tried to show in the case of arithmetic - dissolve the supposed sociological problem of explanation rather than open the way for it.

This line of argument, however, has often been criticized on the ground that this seems to presuppose that practices are therefore incorrigible, i.e., that sociologists (or anyone else for that matter) perforce have simply to assent to the legitimacy of engaging in a practice because, to borrow Wittgenstein’s phraseology, “this language game is played". 5

We take Rawls' main contribution in “Two concepts of rules” for social science to lie in highlighting the importance of strongly distinguishing between challenging someone within a practice or about the practice. Bloor's number wheel example is not a challenge to calculations made with our default arithmetic (the correct change to a ten pound note to an item priced $£ 1.84$ is still £8.16), but only to the supposed 'justifications' for insisting that $2+2$ must equal 4 (or that $10.00-1.84$ must equal 8.16). However, this challenge is shown to be ineffective because it treats the justification of moves within the practices of default arithmetic as if they presuppose some ultimate justification of that system. The system of default arithmetic is conventional, but that does not entail that $2+2=4$ is an optional element within it, for, as a constitutive rule, it is definitive of that system. Our line of argument does not legislate on the general possibility of calling any given practice into question, but points to some of the difficulties arising in cases where the practice's rules are constitutive and this fact is disregarded. We have argued that the fact that many people might insist that $2+2$ must equal 4 should be seen as an indication that they

\footnotetext{
5 “Our mistake is to look for an explanation where we ought to look at what happens as a 'protophenomenon'. That is, where we ought to have said: this language-game is played.” (Wittgenstein, 1953, §654).
}

Greiffenhagen, C. and W. Sharrock (2009). Two concepts of attachment to rules. Journal of Classical Sociology 9 (4), 405-427. 
take the expression to be one posed within our 'default' arithmetic, rather than as evidence of any foundationalist (ideological) attachment to that system.

Operating 'within' a practice and reflecting 'about' a practice are not the same thing, since they are done under the auspices of different 'offices' and, as Rawls (1995, p. 11) points out: “Until one knows these things one doesn't know what the institution is whose justification is being challenged [...]”. Whilst in Rawls' case it is important to keep separate the offices of judge (who is operating within current law) and legislator (who may reflect upon, and even change, current law), in the case of mathematics it is important to distinguish between questions which can make sense to an everyday user operating within a particular arithmetic (such as 'Do you have to say '4' is the correct answer to 'What does 2 add 2 make?") and questions that arise about a particular arithmetic (e.g., puzzlements about the philosophical, historical or sociological significance of the fact that there is a plurality of heterogeneous number systems). Awareness of Rawls' thoughts on the nature of practices can still contribute to the elimination of these latter kinds of puzzlement and may be helpful not only with respect to understanding mathematics but many other practices as well.

\section{Acknowledgements}

We would like to thank Anne Rawls for helpful comments on an earlier draft. Christian Greiffenhagen gratefully acknowledges the support of the Simon Research Fellowship (which is funded through an endowment made to the University of Manchester) and of the British Academy (through a Postdoctoral Fellowship and a Small Research Grant).

\section{References}

Abercrombie, N., S. Hill, B. S. Turner (1986). Sovereign Individuals of Capitalism. London: Allen \& Unwin.

Barnes, B., D. Bloor, and J. Henry (1996). Scientific Knowledge: A Sociological Approach. London: Athlone.

Bloor, D. (1973). Wittgenstein and Mannheim on the sociology of mathematics. Studies in History and Philosophy of Science 4 (2), 173-191.

Bloor, D. (1976). Knowledge and Social Imagery. London: Routledge \& Kegan Paul.

Bloor, D. (1983). Wittgenstein: A Social Theory of Knowledge. London: Macmillan.

Greiffenhagen, C. and W. Sharrock (2009). Two concepts of attachment to rules. Journal of Classical Sociology 9 (4), 405-427. 
Bloor, D. (1994). What can the sociologist of knowledge say about $2+2=4$ ? In P. Ernest (Ed.), Mathematics, Education and Philosophy: An International Perspective, pp. 21-32. London: Falmer.

Bloor, D. (1997). Wittgenstein, Rules and Institutions. London: Routledge.

Davis, P. J. and R. Hersh (1981). The Mathematical Experience. Boston: Birkhäuser.

Garfinkel, H. (1963). A conception of, and experiments with, 'trust' as a condition of stable concerted actions. In O. J. Harvey (Ed.), Motivation and Social Interaction, pp. 187-238. New York, NY: Ronald Press.

Garfinkel, H. (1967). Studies in Ethnomethodology. Englewood Cliffs, NJ: PrenticeHall.

Garfinkel, H. (2002). Ethnomethodology's Program: Working Out Durkheim's Aphorism. Lanham, MD: Rowman \& Littlefield.

Greiffenhagen, C. and W. Sharrock (2006a). Logical relativism: logic, grammar, and arithmetic in cultural comparison. Configurations 14 (3), 275-301.

Greiffenhagen, C. and W. Sharrock (2006b). Mathematical relativism: logic, grammar, and arithmetic in cultural comparison. Journal for the Theory of Social Behaviour 36 (2), 97-117.

Greiffenhagen, C. and W. Sharrock (2007). Linguistic relativism: logic, grammar, and arithmetic in cultural comparison. Language \& Communication 27 (1), 81-107.

Greiffenhagen, C. and W. Sharrock (2008). Where do the limits of experience lie? abandoning the dualism of objectivity and subjectivity. History of the Human Sciences 21 (3), 70-93.

Mackie, J. L. (1966). Proof. Proceedings of the Aristotelian Society, Supplement 40, 23-38.

Mannheim, K. (1936). Ideology and Utopia: An Introduction to the Sociology of Knowledge. London: Routledge \& Kegan Paul.

Rawls, J. (1955). Two concepts of rules. Philosophical Review 64 (1), 3-32.

Schatzki, T. R., K. Knorr-Cetina, and E. von Savigny (Eds.) (2001). The Practice Turn in Contemporary Theory. London: Routledge.

Winch, P. (1964). Understanding a primitive society. American Philosophical Quarterly 1, 304-324.

Winch, P. (1990 [1958]). The Idea of a Social Science and its Relation to Philosophy (Second ed.). London: Routledge.

Wittgenstein, L. (1953). Philosophical Investigations (Translated by G.E.M. Anscombe). Oxford: Basil Blackwell.

Wittgenstein, L. (1976). Wittgenstein's Lectures on the Foundations of Mathematics, Cambridge, 1939 (Edited by C. Diamond). Chicago: University of Chicago Press.

Wittgenstein, L. (1978). Remarks on the Foundations of Mathematics (Edited by G. H. von Wright, R. Rhees and G. E. M. Anscombe. Translated by G. E. M. Anscombe) (Third ed.). Oxford: Basil Blackwell. 